\title{
Überstunden erhöhen das Schlaganfallrisiko
}

— Berufstätige, die viele Überstunden anhäufen, haben ein signifikant erhöhtes Schlaganfallrisiko. Dies ist das Ergebnis einer großen Metaanalyse mit Daten von 528.908 Arbeitnehmern.

Während der im Schnitt 7,2 Jahre dauernden Beobachtungszeit traten bei den Probanden 1.722 Schlaganfälle auf. Dabei fand sich ein dosisabhängiger Zusammenhang: Wer 41 bis 48 Wochenstunden zusam- menbrachte, hatte ein um relative $10 \%$ erhöhtes Schlaganfallrisiko, bei 49 bis 54 Stunden lag der Risikoanstieg bei $27 \%$.

Der Zusammenhang zwischen Überstunden und Schlaganfallrisiko ist nach Ansicht der Autoren plausibel: So reagiert der Körper bei überlasteten Menschen mit Stress; ein Phänomen, das beim plötzlichen „Tod durch Überarbeitung" offenbar eine Rolle spielt. Wer viele Überstunden macht, sitzt zudem

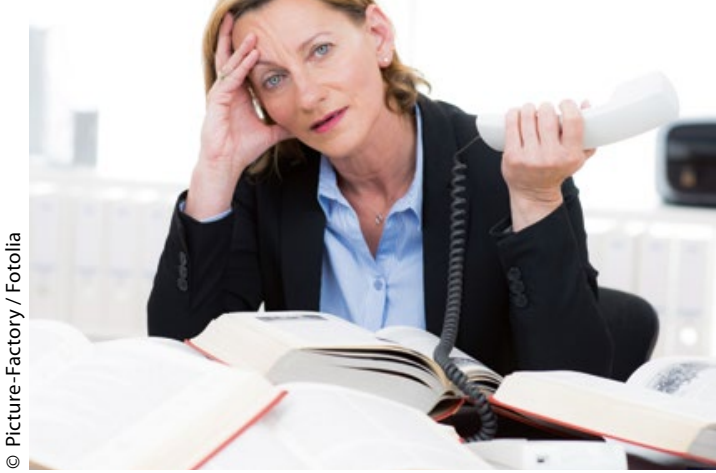

länger; auch dies kann ein vaskuläres Ereignis begünstigen. Drittens neigen Workaholics zum verschärften Trinken - ein Risikofaktor für Schlaganfälle jeden Typs.

eo .

\section{Dampf mit Suchtpotenzial}

\section{Verleitet die E-Zigarette Jugendliche zum Tabakrauchen?}

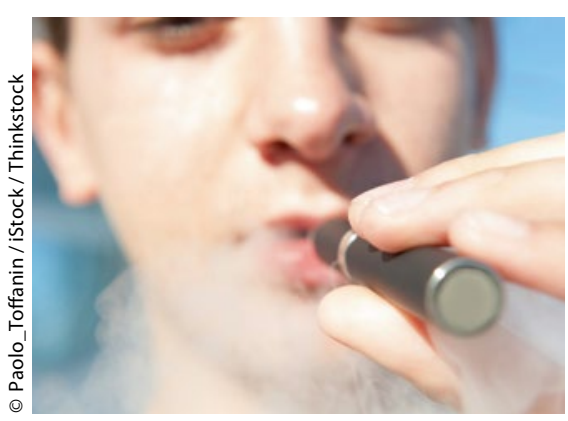

_ Die Bundesregierung diskutiert ein Abgabeverbot für E-Zigaretten an Minderjährige. Ein Argument dafür liefert eine aktuelle Studie aus den USA.

In dieser prospektiven Untersuchung begannen jugendliche E-Zigaretten-Dampfer häufiger mit dem Tabakrauchen als ihre Altersgenossen, die niemals dem Dampfen gefrönt haben: $30,7 \%$ der anfänglichen E-Zigaretten-Konsumenten qualmten sechs Mona- te nach Studienbeginn auch Zigaretten, Zigarren oder Wasserpfeifen, aber nur $8,1 \%$ der Jugendlichen, die niemals eine E-Zigarette angerührt hatten. Zwölf Monate später konsumierten entsprechend 25,2 und 9,3\% der Teilnehmer bereits Tabak. Für die regelmäßigen E-Zigaretten-Dampfer war es damit mehr als doppelt so wahrscheinlich, mit dem Tabakrauchen anzufangen. vsc . - Leventhal AM et al. JAMA 2015;314(7):700-707

\section{Ein Krankenhaus ist keine Rückenschule}

Immer mehr Patienten haben „Rücken“ und liegen damit im Krankenhaus, ohne dass ihnen geholfen wird. Und das, obwohl immer öfter operiert wird. Diese Meldung, von den Krankenkassen in Umlauf gebracht, wurde auf der Titelseite der BILD-Zeitung quasi als Sensation verkauft. Dabei dürfte allseits bekannt sein, dass ein Krankenhaus keine Rückenschule ist. Im Gegenteil, alle, die schon einmal im Krankenhaus gelegen haben, wissen um die Qualität der Matratzen dort. Wenn man nicht im Krankenhaus Rückenschmerzen bekommt, ja wo denn dann? Viele Patienten, die primär wegen einer anderen Erkrankung stationär behandelt werden, gehen bereits nach einigen Tagen mit "Rücken" nach Hause. Böse Zungen behaupten sogar, die Matratzen seien ein willkommenes Mittel, um die Klinikverweildauer zu verkürzen. Allzu oft wird versucht, dem Massenphänomen „Rückenschmerzen" mit Röntgen, CT und MRT entgegenzuwirken, leider ohne nennenswerten Erfolg. Kaum ein Patient verspürt nämlich Besserung, wenn er die Segnungen einer überzogenen Diagnostik, die zwar nicht Evidenz-, aber Eminenz-basiert ist, genießen durfte.

Doch wenn Rückenschmerzen im Krankenhaus eher schlimmer als besser werden, sollte man Patienten dringend da- von abraten, ein solches wegen solcher Beschwerden überhaupt aufzusuchen. Gleiches gilt für den gar nicht so seltenen Fall, dass der Rücken unter's Messer soll, was sogar nach Meinung der Experten in den meisten Fällen nichts bringt. Die Operation ist zwar nicht umsonst - das können die Kassen bestätigen - aber unnütz. „Rücken“ braucht eben Geduld und Zeit, und Sie als Hausarzt sollten Ihre Patienten mit Kreuzschmerzen deshalb solange bei guter Laune halten, bis die Natur sie geheilt hat. Und die Natur lässt sich bisweilen gerade bei „Rücken“ viel, viel Zeit.

Dr. Peter Stiefelhagen . 